\title{
Counting beans in the degree factory
}

(Some practical meta-ethical reflections on academic integrity in Australian universities)

\author{
John Atkins and William Herfel \\ Griffith University and University of Western Sydney, Australia \\ j.atkins@griffith.edu.au; wmherfel@yahoo.com.au
}

\begin{abstract}
This paper examines how material conditions constrain the capacity to act with academic integrity, particularly in the context of severe resource limitations within Australian higher education. It describes the current situation in Australian universities illustrating this with statistics as well as the authors' experiences. Drawing on the recent report on plagiarism policy and implementation at The University of Newcastle produced by the St. James Ethics Centre, the paper shows how policies and procedures can run aground due to resource scarcity. It also explores the breakdown of traditional academic culture and its impact on integrity, making reference to the University of Maryland Student Honor Code. Finally, the paper raises the question of what constitutes ethical action when resources become stretched to the breaking point.
\end{abstract}

Keywords: academic integrity, higher education reform, university, plagiarism

\section{Introduction}

Structural changes which have taken place in Australian higher education over the past 15 years are well documented. Somewhat euphemistically labelled as 'reform', they have resulted in reduced government funding for public universities whilst enrollments have increased more than $30 \%$. Much of the shortfall has been recovered by increasing the number of full-fee paying students (mainly coming from outside Australia) nearly fourfold, making education Australia's sixth largest export industry. A good overview of the current state of Australian higher education was presented in the recent ABC Four Corners documentary, “The Degree Factories” (Fullerton, 2005). At the same time, academic staff levels have increased little, resulting in a near doubling of student staff ratios during the past decade and a half ${ }^{1}$. Trends over the decade 1990-2000 and their implications are discussed insightfully in the 2001 report to the Chifley Research Centre, The Comparative Performance of Australia as Knowledge Nation (Considine, Marginson \& Sheehan, 2001). A key finding of the report is that the reforms in higher education have resulted in a major shift from knowledge production to knowledge reproduction and transmission. Insofar as the ABC documentary reflects the current reality, the trends identified in the Chifley Centre report have at best continued, but most likely accelerated. In the first section of this paper we will present an overview of this situation supplemented by observations from our experience of this transition.

No doubt the much publicized case of plagiarism at The University of Newcastle in $2003^{2}$ has been a provocative stimulus to initiating discourse about academic integrity in our context. Although it does display features that would be grist for our mill, the notoriety of this event is one of the reasons we do

\footnotetext{
${ }^{1}$ Student-staff ratios have been steadily climbing; the statement in the text is based on a conservative estimate (on the low side) from numerous sources of the current figure. An exact number, properly documented, appears in the text below.

${ }^{2}$ This case will be familiar to our Australian colleagues. The incident involved administrators at The University of Newcastle turning a blind eye to plagiarism reported by an academic staff member at their Malaysia-based business studies program, and a subsequent cover up. It was eventually investigated by the New South Wales Independent Commission Against Corruption (ICAC). See Independent Commission Against Corruption (2005).
} 
not want to especially focus on it. The other reason is its extremity: hopefully most of us will never be involved in a situation that could result in being asked to stand before a major commission of inquiry such as ICAC. Instead we want to focus on issues concerning academic integrity that all of us face periodically. Nevertheless, one of the results of the Newcastle episode was to bring into prominence the significance of appropriate handling and the cost of detecting plagiarism. A report which the university commissioned the St. James Ethics Centre to produce, Independent enquiry: Plagiarism policies, procedures and management (Longstaff, Ross \& Henderson, 2003) has generated considerable interest in this regard. Given its ethical orientation, the St. James report raises a number of the problems experienced by many in academia. The second section of our paper will show how a selection of the issues raised by Longstaff et al. (2003) can only be addressed in the context of the higher education reforms cited above.

Recently in Australia, following global trends, there has been increased interest in creating and enforcing plagiarism policies, as well as improving plagiarism detection by the use of proprietary software programs (Carroll, 2004; Eckersley \& Stokes, 2004; McCabe, 2004). In contrast to these 'enforcement strategies' there is an alternative, common in US universities, called an 'honor code'. Whilst we do not necessarily advocate an honour approach to academic integrity for Australia, we do think that aspects of that system are worth more than a passing inspection. At first glance, from an ethical perspective, honour codes have two advantages: they are based on 'honour', arguably a fundamental human value, and secondly, they give students ownership (through participation) of the process of enforcement. Section three of our paper will briefly examine the University of Maryland Student Honor Council Code of Academic Integrity.

Our discussions in preparation for this paper revealed a wide range of concerns that we think have contributed to the current situation. Here we intend to investigate just two aspects of this much larger problem: some of the ways in which ethical issues have been marginalized by economic constraints and how this has affected working conditions in our institutions. ${ }^{3}$ In an article such as this we cannot suggest how to redress all the many and complex problems concerning academic integrity in contemporary Australia but since it will always be academics themselves who are at the forefront of coping with difficulties created by policy change, as practicing philosophers, we feel well placed to pin-point a few key issues. Examining ways universities have reacted to the problem of plagiarism is also useful since it can be seen as characteristic of their responses to similar ethical quandaries. Plagiarism in particular, as well as academic integrity in general, is becoming a global concern. Many of the strategies deployed internationally are similar to those canvassed in this paper. Thus we have produced these 'practical meta-ethical reflections', which we expect to be useful beyond just the Australian context.

The irony of such a label will not be lost on readers with any background in moral theory. In contemporary philosophical discussions 'meta-ethics' concerns foundational questions. For example, what is the theoretical basis for ethical reasoning? However, this is not our concern here. In our view, applied ethical judgment requires a practical meta-ethics as well. That is, we must understand the current state of play of our practical situation in order to make sound ethical decisions. It is on such practical foundations that we focus. There can be little doubt that recent bureaucratic changes in Australian universities have increased both the occurrence and the difficulty of ethical dilemmas concerning academic integrity. More importantly, it appears some current strategies aimed at addressing these problems expeditiously may, paradoxically, compound the growing crisis in the long term. The paper will conclude by raising one crucial question concerning academic integrity: How can we be ethical in the face of diminishing resources?

\footnotetext{
${ }^{3}$ We intend to address some of the many other concerns in future work.
} 


\section{The changing face of university education in Australia}

Here we are forced to be schematic; nevertheless Australian readers will be familiar with this story. Since the Dawkins' reform of higher education in the late $1980 \mathrm{~s}^{4}$ universities in Australia have been in a perpetual state of 're-organisation'. In general, total student numbers have doubled, whilst government expenditure in the university sector has declined. The difference has come from several sources. The largest new contributions to university funding have come from the introduction of the Higher Education Contribution Scheme (HECS) and a massive increase in full-fee paying students from overseas. The proportion of staff involved in teaching has declined. There has been an increased casualisation of teaching staff. Student/staff ratios increased dramatically. In their report, Considine, Marginson and Sheenan (2001) provide alarming statistics to reinforce these general conclusions. Total student numbers rose from 485,066 in 1990 to 695,485 in 2000. Government funding per student was $\$ 8724$ in 1989 but had fallen to $\$ 6826$ by 1999 , whilst the percentage of funding from government sources had dropped from 70\% in 1989 to $49 \%$ in 1999. Overseas student numbers increased from 24,998 to 95,607 in the ten year period 1990 to 2000. The proportion of staff involved in teaching has dropped from $42.7 \%$ to $37.6 \%$ during the same decade, whilst the proportion of teaching time provided by casual labour had grown to 21\% by 1999 (Considine, Marginson \& Sheehan, 2001). Finally, the most revealing figure from the perspective of constraints on ethical behaviour: the ratio of student to staff in 1987 was $12: 1$, by 2004 it had grown to $21: 1^{5}$

To some extent the statistics speak for themselves, but they do not tell the whole story. The ways in which these structural reforms have been implemented have placed even greater pressures on delivering education not immediately obvious from the numbers. Take the experience of one of the authors as typical. He joined the lecturing staff in the Department of Philosophy at The University of Newcastle in 1994 when the Dawkins' reforms were well underway. In 1997, in order to rein in costs, the university was restructured (in the corporate sense) by offering approximately 200 academics early voluntary retirement. In 2001-2 another 'restructure' was undertaken. Whilst this time no staff members were lost, the organisational make-up of the university was radically reformed: faculties were reorganised going from eleven to four but, more significantly, departments were abolished replaced by schools. It was not entirely clear what the purpose of the reform was. If it was designed to save money, it failed miserably: in 2005 a deficit of around $\$ 20$ million $^{6}$ was reported at the same time it was announced that another restructure was imminent, this time requiring over 400 job losses.

This sort of incessant change causes a certain amount of stress for a university's staff, and this stress inevitably will have some impact on individuals' ability to tackle issues of integrity. In this case, and clearly the experience at Newcastle was not atypical, repeat reform and its accompanying on-going administrative burden has impeded the accomplishment of many academic tasks and this, we argue, has led to a corresponding erosion of academic integrity. The most significant example of this came with the restructuring of departments into schools. Prior to the amalgamation, the department was the fundamental administrative structure for dealing with such day to day academic activities as teaching documentation, examination, curriculum, workload, and so forth. Plagiarism cases were generally handled through informal consultation with the head of department, with (rarely occurring) serious cases referred to the dean of the faculty. This process appeared satisfactory, particularly in a small department with a solid sense of community and with sufficient familiarity between its members to enable consistent judgements on departmental policies. But as a result of the 2000 reform the academic unit of the department no longer existed. Despite a massive effort creating procedures and documentation (mostly documentation) for necessary administrative functions dealing with teaching, how to carry out these once straightforward activities was now unclear. It was during this time that

\footnotetext{
${ }^{4}$ John Dawkins was Labor Minister for Employment, Education and Training in the 1980s. His reforms rationalised higher education by amalgamating the universities with vocationally oriented colleges of advanced education. This reform also initiated reduced funding and increased student numbers to the sector as a whole.

${ }^{5}$ This statistic reflects the view from a number of sources. It can be extrapolated with some certainty from Considine, Marginson \& Sheehan, 2001; cf. Marginson, 2005.

${ }^{6}$ The exact figure has remained fluid. University documents have stated a range from \$15 million to \$28 million on various occasions.
} 
many of the policy documents sharply criticised for their inconsistency in the St. James report were created.

This is the crux of the problem: 'Formalised strategies' quite clearly are convenient for policing they create a paper trail and offer some level of protection from litigation or the charge of dereliction of duty. Yet the very creation of these policies could be undermining the general perception of the academy as being a community serving both its members and the society as a whole. A perceived need for formal procedures could well reinforce the assumption that academics act only out of self interest (presumably just like everyone else in an individualistic society?). Contrast this with the, admittedly piecemeal, communal and informal approach described above. For all its weaknesses it appeared to be working and, even if less than perfect, at the very least was more effective than current solutions or even more radical proposals such as plagiarism detection programs. We can identify several factors from the structural reform of higher education that can and have impacted on academic integrity, particularly in the area of plagiarism detection and enforcement: 1 ) the increase in student/staff ratio has placed more burden on staff, 2) high numbers of overseas students may not be familiar with Australian standards of scholarship and 3) increasing reliance on casual staff who may have less experience in the detection of plagiarism. These are compounded by restructuring that increases academic staff administrative workloads, at the same time making policies less clear and procedures more difficult. The most intangible, but perhaps most significant, factor could be a radical change in academic culture in Australia during the past two decades. Simon Marginson (2005, p.2) describes the situation this way:

In Australia, especially when per student public funding declined after 1996, business functions became the driver of development, more than academic capacity. Attention focused on revenues, efficiencies, marketing, administrative modernisation and economies of scale. Institutions grabbed every potential source of public and private finance. When HECS-place funding for domestic participation stopped growing, institutions (even sandstones like Melbourne and Sydney) stepped up high volume medium quality coursework programs for international students in business and IT.

Of course here Marginson is focussing on instrumental aspects of the reform. But was this shift in emphasis from education for its own sake to education for profit perhaps not also accompanied by a shift in ethos? We will revisit this issue of institutional norms in the final section, but first we will look at some issues raised by the St. James review.

\section{Ethics in action}

Section "3.3 Finances and Universities" of the St. James enquiry (Longstaff, Ross \& Henderson, 2003) briefly canvasses some of the issues raised in the earlier section of our paper. They (Longstaff et al. 2003, p. 43) state, "A number of allegations regarding plagiarism at the University of Newcastle and within the university domain in general relate to funding / financial distress." Then in four paragraphs they make the following points:

- This situation brings about the temptation to use questionable means to bring about desirable ends.

- "Tight fiscal constraints" ${ }^{7}$ may play a part in "questions from the media about double standards in relation to the treatment and assessment of international students."

- "Australian universities are becoming increasingly under-resourced ... yet have maintained a reputation for high quality courses and graduates.",

- The universities are a huge asset to Australia with overseas student revenue worth \$947 million (10\% of the 2000 total student revenue); "the cost of failure" (of under-qualified overseas students) can negatively impact on the reputation of Australian universities. (Longstaff, Ross \& Henderson, 2003 p. 43)

\footnotetext{
${ }^{7}$ Here citing a document by then Minister for Education Brendan Nelson.

${ }^{8}$ The second part of this passage is sourced from a report by the Group of Eight, the eight leading research universities in Australia.
} 
Despite the obvious ethical focus of their document, the enquiry failed to explicitly note the ethical issue that concerns us most here; material conditions can often constrain the capacity to act ethically. These constraints occur in a variety of ways, for there can be no doubt that in an under-resourced environment there is both more motivation and more opportunity to act unethically. Many forms of unethical behaviour other than plagiarism, for example, fraudulently presenting, or inventing, experimental findings, are certainly present ${ }^{9}$. What role material conditions in universities play in these cases is not yet clear. However, lack of resources can lead to overwork, and overwork can limit one's ability to detect, and hence react appropriately to, unethical behaviour. ${ }^{10}$ Furthermore, cultural change, for example, a shift in focus to efficiency and competition from such traditional academic values as truth and honesty, can erode — or at least alter — the basis for ethical action.

Within the comments made in the focus groups forming the basis for much of the St. James enquiry, the issues we address here were raised. Again, the report fails to flag the impact resource limitation has on individual ethical action with respect to academic integrity as an issue. In particular, whilst it raises the issue of "Finances and Universities", the report does not cite the fact that student/staff ratios have grown from 13:1 to 21:1 in just over a decade. Obviously, and most significantly, it does not discuss the ethical implications of such growth. We cannot hope to provide an exhaustive review of the focus group comments here, but we will provide a few examples before moving on to address the larger ethical point in more detail.

Exploring the issue of "gaps between stated policy and lived reality", the St. James enquiry evoked the following comments ${ }^{11}$ :

"The issue of plagiarism is difficult and involves a serious amount of stress for staff and students involved. In addition it will involve a serious amount of time, effort and paperwork. It is probable that in a living situation a plagiarism situation can be either ignored or diluted to the extent that it can be passed over. This could be done to limit the stress/workloads involved.”

"wonder [sic] how much plagiarism either goes undetected or ignored particularly by part-time or casual lecturers. This could explain why students in senior years are angry when they are asked to account for or explain why their work or parts of it are plagiarised. They often ask why no one else has raised this with them when they have been preparing assignments like this the whole time they have been at university.”

(Longstaff, Ross \& Henderson, 2003, p.52)

Of course our ethical response to these statements varies depending upon material context. One set of responses is appropriate if the individuals involved are being well looked after by the institution; another is appropriate if this is not the case.

In another section the report states, "The groups [composed of both lecturers and students] were asked to summarise the high-risk areas [of plagiarism]...” (Longstaff, Ross \& Henderson, 2003, p.59). Three of the issues on a long list were:

Teachers handing out the same essay topics and assignments every year. "Its easy for them to mark and easy for us to cheat.” (student)

\footnotetext{
${ }^{9}$ For example see Marris (2006) or Nicol (1989).

${ }^{10}$ It is perhaps ironic that the Newcastle incident, which was the main reason for the St. James enquiry, is a counterexample of the issue we are raising here. If not for the diligence of the lecturer involved in spotting and referring on the allegedly plagiarised work in the first place there would have been no problem. Had the lecturer been so overworked that he overlooked the transgression, there would have been no plagiarism incident at all.

${ }^{11}$ This material is somewhat difficult to reference. In the responses the St. James report mixes summary with direct quotation, using inverted commas to distinguish the quotes. Hence we will indent responses from the report (whether they are long or not), and include inverted commas in the indented sections as they appear in the original document. All bold and italics is in the original, unless otherwise noted.
} 
Large classes, heavy work load - "Students know the lecturer is not going to check every word and every reference-he/she has three hundred assignments to mark - There is a perception in the student culture that it's easy to get away with it.” (student)

"Academic remuneration is not earth shattering — you need outside work — how much time can you spend checking every reference or following up on your suspicion.” (lecturer)

(Longstaff, Ross \& Henderson, 2003, p.59)

When evaluated from within a material context, the situations described here could, depending upon point of view, be indicative of individuals cutting corners or the institution cutting corners. Our ethical assessments toward the individuals involved would vary accordingly. In the course of the enquiry staff members were surveyed on the following question: "What are some of the obstacles (e.g., situations, politics, procedures, ambiguities and complexities) which make it difficult to achieve best practice and policy in the management of plagiarism?” (Longstaff, Ross \& Henderson, 2003, p.63) Some responses were:

"high teaching loads (currently 14 hours of face to face teaching plus administration in the department in which I work), heavy marking loads (I marked 400 items of assessment in the month of June)"

"Ludicrously heavy workloads BOTH staff and student"

"It is time-consuming to track down evidence to support a case of plagiarism and workload pressures increasingly limit the time available to do anything but the bare essentials to keep the place afloat.” (Longstaff, Ross \& Henderson, 2003, p.63)

These responses reinforce some of the points addressed above. Additionally, the comment indicating that students currently suffer additional workloads under the new regime serves to emphasise a vicious positive feedback cycle: overworked students have more incentive to cheat whilst overworked markers are less likely to detect their efforts. It is worthwhile to perform some rough calculations to illustrate the point:

Assume one is responsible for marking the work of 50 students (i.e. 12.5 student/staff ratio) in one semester. Further, and perhaps naively, assume a plagiarism rate of 1\%. If it takes 6 hours on average to investigate, document and respond a plagiarism case, a lecturer will correspondingly spend 6 hours per year or $<1 \%$ total teaching time ${ }^{12}$ so doing. Contrast this with the situation many find themselves in: 200 pieces of marking, with say (very) conservatively, $5 \%$ plagiarism rate ${ }^{13}$. This yields 60 hours per year (or $6.5 \%$ of total teaching time); no doubt actual figures will be considerably higher.

The St. James report (Longstaff, Ross \& Henderson, 2003, p. 4) opens with the following observation:

An important part of [the] context [of the enquiry into plagiarism policies, procedures and management controls at the University of Newcastle] is the high degree of popular scepticism (if not outright cynicism) about the conduct and motives of individuals and organisations. In general the public tends to assume that the demands of self-interest are often opposed to and 'trump' the consistent application of principle. Given this, there has been, in recent years, a growing acceptance of increased regulation and surveillance in the hope that such measures will be a practical alternative to untrustworthy and unreliable regimes of self-regulation.

This is a succinct account of public perception. However, regulation and surveillance we believe can never eliminate the need for human judgement. Regulation may require academics to report all

\footnotetext{
${ }^{12}$ Based on 924 total teaching hours per year (35 hrs/wk X $48 \mathrm{wks} / \mathrm{yr} \times$.55, where the expectation is that $55 \%$ of a full-time academic's job is teaching). Readers may substitute their own numbers if they feel they are more representative. The general point remains the same.

${ }^{13}$ Some research suggests the figure could be much higher. See Carroll (2000) or McCabe (2005).
} 
instances of plagiarism. But what if the academics do not see them? Turning a blind eye is most efficacious at the chalk face. Perhaps surveillance will help? If we take the words of the focus groups seriously, resources are so stretched at the University of Newcastle (and, as we said before, there is no reason to believe Newcastle is unique in this regard) that markers hardly have time to track down any cases of plagiarism they suspect. Where will Australia find the resources to invigilate the invigilators? This is a serious problem. However it gets worse: as the focus groups have pointed out, when systems of regulation and surveillance become cumbersome and unwieldy individuals subject to them are even less likely to cooperate with them. When a system becomes dysfunctional, at what point does it become unethical to turn a blind eye? When does ethics give way to pragmatism; when does such pragmatism begin to undermine traditional institutional values; and how long does this process take before a negative economic impact is felt? The knee-jerk reaction in many parts of the world has been to turn to plagiarism detection programs but here we threaten to introduce a host of new issues and concerns. The use of such software threatens to rewrite what we define as 'plagiarism': are we forced to accept the dictum, "if it passes the program then it is not plagiarized"? Such methods also send a potent message to students and that message is clearly labelled 'enforcement', hardly a traditional value in academe. If, as both of us suspect, these programs will quickly become less effective as students find ways to beat them then we have lost the battle on two fronts. We will not have actually beaten plagiarism and values such as collegiality will have been further eroded in the process. These observations echo one more remark from the St. James focus groups which is worthy of mention. One "of the obstacles ... which make it difficult to achieve best practice and policy in the management of plagiarism” was “[t]reating education as a marketable commodity” (Longstaff, Ross \& Henderson, 2003, p.63). This remark, coupled with the foregoing discussion, leads to a final point.

\section{Honour vs. enforcement}

Resource scarcity per se causes problems for the detection of plagiarism and the enforcement of academic integrity policies. By now we hope that we have made clear that government education policies, particularly those aimed at funding, have decreased resources available for higher education. However, here we want to revisit the issue of the change of ethos that has occurred within the academy over the past two decades. Not only has the Australian government cut its per student contribution to higher education, it has put into place policies that encourage, to borrow the words of our earlier anonymous focus group participant, "treating education as a marketable commodity". These policies, as well as their results and implications, have been discussed at length in the documents cited above and elsewhere. Their conclusion is that more damaging to integrity than lack of funding is the response of universities to scarcity. Australian university education has been aggressively marketed overseas to such an extent that it has become more than a billion dollar export commodity. Such effort engenders a specific value system. Academic excellence has been forced to give way to economic efficiency. Plagiarism detection and enforcement policies and strategies now become seen as sensible ways to preserve the value of the Australian university brand, at least as it is currently being promoted. What these stated aims conceal, though, is an underlying malaise.

Some universities in the United States employ a different strategy. Based on a tradition, dating at least back to 1784 at the College of William and Mary, many universities adopt an honour code. The University of Maryland Student Honor Council Code of Academic Integrity ${ }^{14}$ is prefaced as follows:

The University is an academic community. Its fundamental purpose is the pursuit of knowledge. Like all other communities, the University can function properly only if its members adhere to clearly established goals and values. Essential to the fundamental purpose of the University is the commitment to the principles of truth and academic honesty. Accordingly, The Code of Academic Integrity is designed to ensure that the principle of academic honesty is upheld. While all members of the University share this responsibility, The Code of Academic Integrity is designed so that special responsibility for upholding the

\footnotetext{
${ }^{14}$ We have chosen the University of Maryland rather than, say, the more traditional College of William and Mary as an example quite consciously. Whilst William and Mary is a small elite institution, Maryland is a large public university.
} 
principle of academic honesty lies with the students. (University of Maryland Student Honor Council)

Some may find this statement rather old fashioned. However, it illustrates two points: it is still possible to at least create the illusion that academic integrity at a large state university is based on traditional academic values and students can be (and still are in some communities) entrusted to play a role in upholding academic integrity. Students are required at the University of Maryland to sign an honour pledge and there are clear procedures for penalising violators. However, students actually make up a majority of the voting members of the board that enforces the code. Perhaps the highest value in a free market system is competition. Certainly competition plays a healthy role in traditional educational systems. Nevertheless, basing universities on market values alone, in the absence of traditional academic values, will prove to degrade systems of higher education in the long run. Economic efficiency can lead to pedagogically dubious practices. Perhaps a threshold has already been crossed in Australia whereby economic efficiency has overtaken educational integrity. The question needs to be asked whether this transition is reversible and, perhaps more pragmatically, whether current practice is sustainable.

One central value in traditional academic communities is the student-teacher relationship. The section entitled "Student Lecturer Relationship Distance" of the St. James enquiry report (Longstaff, Ross \& Henderson, 2003. p.80) explores the hypothesis that "the wider the distance between student and lecturer the greater the temptation to plagiarise.” After canvassing a few opinions on the issue they summarise as follows:

It seems to make sense that plagiarism is more likely if you do not personally know your lecturer: students are less likely to ask for guidance; teachers are less likely to know they need it; and being found plagiarising by a 'stranger' is perhaps not as great a concern as being discovered by someone you know and respect.

So... this simply means more care and caution is needed in these situations.

(Longstaff, Ross \& Henderson, 2003, p. $80^{15}$ )

Of course, no one would deny a duty of care with respect to academic integrity within the context of the delivery of any course - independent of the 'distances' involved. The question remains how is this best achieved? At a number of universities where we have both worked taking 'more care' in this regard has been 'attended to' by inserting a five minute mention of detecting plagiarism and appropriate marking techniques into a sessional and casual teachers' workshop. ${ }^{16}$ To presume that new staff can acquire the requisite skills within such time frames shows either that those administrators who have made these decisions have little idea about the levels of training that go into making good teachers or have cynically responded to a problem by merely creating paperwork and procedures stand as evidence that they have addressed it. Clearly, the issues raised by over-reliance on large classes and distance delivery, compounded by a material culture which trivialises the student-lecturer relationship, is not just a simple matter of exercising extra 'care and caution' or even being able to point to the fact that the university has included in its workshops a component addressing such matters.

Care and caution require financial resources. Individuals ought not to be put in a position where they must perform beyond the call of duty on a continual basis. Without appropriate resources this is what institutions of higher education require of their academic staff, and this form of economic determinism currently is manifesting itself at every level of our universities' bureaucracies. This is not just an ethical issue for individual staff members; it also gives rise to an ethical dilemma at the institutional level. All else being equal, large classes and distance delivery are efficient, in the economic rationalist sense, so long as all goes well. Even if we leave to one side issues of intellectual quality and academic values, universities are stuck in a bind: without pushing the envelope on economic efficiency they risk

\footnotetext{
${ }^{15}$ Ellipsis in original; emphasis ours.

${ }^{16}$ Further measures will almost certainly include requiring submission of most university work to automated plagiarism detection software programs which we have already argued are of limited value.
} 
falling behind due to competition from institutions willing to cut corners. ${ }^{17}$ Which is preferable: an ethically healthy tertiary sector with few students and little funding or a well funded one with a reputation for unscrupulous corporate practices that will eventually lose students and funding as well? These are the obvious questions of political economy raised by our analysis, but addressing them in detail is beyond our brief. Clearly current university policies to combat plagiarism fail to address a deeper question of personal importance to practitioners within academe: on the assumption that our characterisation of the material situation is roughly accurate, how does one act ethically within such a system?

Between them John Atkins and Bill Herfel have nearly forty years of university teaching experience on five continents. John Atkins is a philosopher, specialising in Wittgenstein and the Philosophy of Science. He also teaches courses on Ethics, Metaphysics, History of Modern Philosophy and Environmental Philosophy. With a PhD in philosophy Bill Herfel has been researching chaos and complexity in scientific models for twenty years, most recently applying it to theory, practice and research methodology of Chinese medicine. Whilst they both have considerable experience teaching a range of core philosophy courses, John and Bill have also coordinated large classes aimed at teaching philosophy to students of disciplines outside the humanities (including science, engineering, psychology and business).

\section{References}

Carroll, J. (2000). What kinds of solutions can we find for plagiarism? Teaching News. Oxford Brookes University. November. Retrieved September 3, 2005, from http://www.heacademy.ac.uk/embedded_object.asp?id21633\&filename=carroll

Carroll, J. (2004). Five years down the road: An interim report from Oxford Brookes University. Symposium on Promoting Academic Integrity: New Policies, Practices and Procedures. Newcastle City Hall. November 24, 25. Retrieved August 7, 2005, from http://www.newcastle.edu.au/conferences/academic-integrity/papers/ Day1Sess5JudeCarrollPresentation5Yrs.ppt.

Considine, M., Marginson, S. \& Sheehan, P. (2001). The comparative performance of Australia as a knowledge nation. Report prepared for the Chifley Research Centre. Retrieved August 7, 2005, from http://www.education.monash.edu.au/centres/mcrie/docs/ researchreports/chifley-knowledge-nation-rev2106.pdf.

Eckersley, C. \& Stokes, A. (2004). Academic integrity: Resource and support framework. Symposium on Promoting Academic Integrity: New Policies, Practices and Procedures. Newcastle City Hall. November 24, 25. Retrieved August 7, 2005, from http://www.newcastle.edu.au/conferences/academicintegrity/papers/Day2Sess4Eckers\&Stokes.ppt.

Fullerton, T. (reporter) (2005). The degree factories (transcript). Four Corners. Australian Broadcasting Corporation. Retrieved August 26, 2005, from http://www.abc.net.au/ 4corners/content/2005/s1401933.htm.

Independent Commission Against Corruption. (2005). Report on investigation into the University of Newcastle's handling of plagiarism allegations. Retrieved March 29, 2006, from http://www.icac.nsw.gov.au/files/pdf/Orion_pub2_97i2.pdf.

Longstaff, S., Ross, S. \& Henderson, K. (2003). Independent enquiry: plagiarism policies, procedures and management controls for the University of Newcastle. Retrieved August 22, 2005, from http://www.newcastle.edu.au/services/academic-integrity/files/st-james-ethics-centrereport.pdf.

\footnotetext{
${ }^{17}$ Perhaps a marketing niche opens for some of those academies that chose not to go down this path, but currently this would be a very risky strategy to all but the highest profile institutions.
} 
Marginson, S. (2005). Diversity in the Nelson system. Prepared for Campus Review, June. Retrieved August 8, 2005, from http://www.education.monash.edu.au/centres/mcrie/docs/ selectedmediaarticles/campus-review-diversity-210605.doc.

Marris, E. (2006). Should journals police scientific fraud? Nature 439 (7076), 520-521.

McCabe, D. (2004). The US and Canadian Experience. Symposium on Promoting Academic Integrity: New Policies, Practices and Procedures. Newcastle City Hall. November 24, 25. Retrieved August 7, 2005, from http://www.newcastle.edu.au/conferences/academicintegrity/papers/DAY1Sess2McCabe.ppt.

McCabe, D. (2005). Cheating among college and university students: A North American perspective. International Journal for Educational Integrity, 1(1). Retrieved April 4, 2006, from http://www.ojs.unisa.edu.au/journals/index.php/IJEI/issue/current

Nicol, B. (1989). McBride: Behind the Myth. Crows Nest. Australian Broadcasting Corporation.

University of Maryland Student Honor Council. Code of Academic Integrity. Retrieved August 8, 2005 from http://www.studenthonorcouncil.umd.edu/code.html. 